\title{
Planning Target Volume
}

National Cancer Institute

\section{Source}

National Cancer Institute. Planning Target Volume. NCI Thesaurus. Code C82606.

A geometrical concept defined to select appropriate beam arrangements, taking into

consideration the net effect of all possible geometrical variations, in order to ensure that the prescribed dose is actually absorbed in the clinical target volume. 